\title{
Metabolic enzyme clustering by coiled coils improves the biosynthesis of resveratrol and mevalonate
}

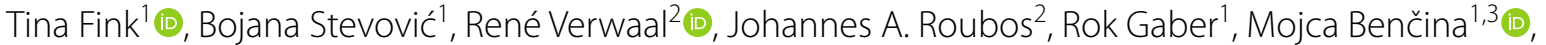 \\ Roman Jerala ${ }^{1,3^{*}}$ (1) and Helena Gradišar ${ }^{1,3^{*}}$ (i)
}

\begin{abstract}
The clustering of biosynthetic enzymes is used in nature to channel reaction products and increase the yield of compounds produced by multiple reaction steps. The coupling of multiple enzymes has been shown to increase the biosynthetic product yield. Different clustering strategies have particular advantages as the spatial organization of multiple enzymes creates biocatalytic cascades with a higher efficiency of biochemical reaction. However, there are also some drawbacks, such as misfolding and the variable stability of interaction domains, which may differ between particular biosynthetic reactions and the host organism. Here, we compared different protein-based clustering strategies, including direct fusion, fusion mediated by intein, and noncovalent interactions mediated through small coiled-coil dimer-forming domains. The clustering of enzymes through orthogonally designed coiled-coil interaction domains increased the production of resveratrol in Escherichia coli more than the intein-mediated fusion of biosynthetic enzymes. The improvement of resveratrol production correlated with the stability of the coiled-coil dimers. The coiled-coil fusion-based approach also increased mevalonate production in Saccharomyces cerevisiae, thus demonstrating the wider applicability of this strategy.
\end{abstract}

Keywords: Designed coiled-coil dimers, Enzyme clustering, Biosynthesis, Resveratrol, Mevalonate

\section{Introduction}

The biosynthesis of complex compounds involves several enzyme catalysts, which need to act consecutively on the reaction substrates and intermediates to produce the desired end product. Natural enzymes are frequently organized into clusters, such as in large enzyme complexes (Conrado et al. 2008) or in microcompartments (Colin et al. 2015; Polka et al. 2016). This offers several benefits, including increased production yield, decreased toxicity by intermediates, and decreased sidereaction metabolic flux. Typically, biosynthetic reactions performed in the host chassis by multiple ectopically

\footnotetext{
*Correspondence: roman.jerala@ki.si; helena.gradisar@ki.si

${ }^{1}$ Department of Synthetic Biology and Immunology, National Institute of Chemistry, Hajdrihova 19, 1000 Ljubljana, Slovenia

Full list of author information is available at the end of the article
}

expressed enzymes from different organisms have not been optimized; in such cases, however, enzyme clustering may increase the production yield (Jandt et al. 2013; Castellana et al. 2014; Ji et al. 2016). Several strategies have been developed and have been reported to achieve enzyme clustering, including covalent enzyme fusions (Zhang et al. 2006;), noncovalent assembly through the fusion of enzyme to protein-protein interaction domains (Dueber et al. 2009; Diener et al. 2016), the fusion of enzymes to DNA- or RNA-binding domains (in combination with DNA/RNA scaffolds) (Delebecque et al. 2011; Conrado et al. 2012; Sachdeva et al. 2014), and the coupling of enzymes to oligonucleotides that direct them into the designed DNA nano-scaffolds (Ke et al. 2016). However, for the spatial organization of a broad range of enzymes in desirable and optimal microenvironments for reaction sequences, a versatile protein scaffolds from
Springer Open (c) The Author(s) 2020. This article is licensed under a Creative Commons Attribution 4.0 International License, which permits use, sharing, adaptation, distribution and reproduction in any medium or format, as long as you give appropriate credit to the original author(s) and the source, provide a link to the Creative Commons licence, and indicate if changes were made. The images or other third party material in this article are included in the article's Creative Commons licence, unless indicated otherwise in a credit line to the material. If material is not included in the article's Creative Commons licence and your intended use is not permitted by statutory regulation or exceeds the permitted use, you will need to obtain permission directly from the copyright holder. To view a copy of this licence, visit http://creativeco mmons.org/licenses/by/4.0/. 
natural and unnatural protein, and peptide domains have been extensively studied in last decade (Lee et al. 2012; Wang and Yu 2012; Yang et al. 2017; Li et al. 2018; Schmidt-Dannert et al. 2018; Zhang et al. 2018, 2019; Lim et al. 2019).

Each clustering strategy has certain advantages and drawbacks. These can depend on the specific reactions and enzymes in question. Additionally, the efficiency of each strategy may depend on the host chassis since different cellular environments (such as the reducing potential and the presence of folding chaperones or other cellular components) may affect the efficiency of each strategy. To minimize the metabolic burden of synthesizing new proteins in the production organism, the clustering domains should be small in size, and, above all, they should not interfere with the other host cellular components. Here, we have compared different enzyme-clustering strategies for the biosynthesis of resveratrol and mevalonate, both commercially interesting products. The use of clustering to increase the production of resveratrol and mevalonate was investigated prior to the use of several different approaches (Halls and Yu 2008; Dueber et al. 2009; Conrado et al. 2012) and can be said, therefore, to represent an appropriate benchmarking model. We anticipated that utilizing a strategy of enzyme clustering via designed coiled-coil interaction domains would avoid problems connected to the folding of multi-enzyme complexes. Our previous studies revealed the orthogonality of de novo designed coiled coils (Gradišar and Jerala 2011; Drobnak et al. 2017), which are suitable for the fusion of small coiled-coil-forming domains to different enzymes on selected biosynthetic pathways. We demonstrate the efficiency of this method in increasing production yields for resveratrol in bacteria. Finally, the study also finds that coiled-coil interaction-based clustering improves the biosynthesis of mevalonate in yeast, thus demonstrating the wider applicability of this strategy.

\section{Materials and methods Construction of plasmids}

The enzymes with $\mathrm{N}$-terminal His-tag from a resveratrol biosynthetic pathway, 4-coumaroyl-CoA ligase (4CL) from Arabidopsis thaliana, and stilbene synthase (STS) from Vitis vinifera (Wang et al. 2011) were codon optimized for expression in E. coli and cloned into a pET19b vector. The $\mathrm{N}$ - and $\mathrm{C}$-terminal intein fragments (IntN and $\mathrm{IntC}$ ) of the NpuDnaE intein for covalent intein fusion were obtained from the pSKDuet01 (Addgene plasmid \# 12172). The direct fusion of 4CL and STS with a 10-amino acid residue linker and $\mathrm{N}$-terminal His-tag was cloned into pET19b. The fusions of $4 \mathrm{CL}$ and STS with different coiled-coil-forming domains (CC), C-terminally fused to 4CL and STS with N-terminal His-tag, were cloned into pET19b. The co-expression of plasmids pET19b-(4CL-STS), pET19b-(4CL:intN-intC:STS), and pET19b-(4CL:CC-STS:CC) contained a tandem of ${ }^{H i s} 4 C L$ and ${ }^{H i s} S T S$, His $4 C L: i n t N$ and His intC:STS, or His $4 C L: C C$ and ${ }^{H i s} S T S$ :CC genes (each under the control of a separate T7 promoter, RBS site, and T7 terminator), respectively.

\section{Bacterial strains, media, and growth conditions for resveratrol production}

Escherichia coli strain BL21(DE3)pLysS (Invitrogen) was transformed with respective constructs and grown at $37{ }^{\circ} \mathrm{C}$ overnight (160 rpm) in LB medium for inoculum preparation. Bacterial cultures were transferred to $100 \mathrm{~mL}$ of fresh 2YT medium with antibiotics (ampicillin and chloramphenicol at concentrations of $50 \mu \mathrm{g} / \mathrm{mL}$ and $34 \mu \mathrm{g} / \mathrm{mL}$, respectively) and grown until $\mathrm{OD}_{600}$ reached 0.6. After induction with $0.7 \mathrm{mM}$ IPTG, cultures were grown for an additional $3 \mathrm{~h}$ at $37^{\circ} \mathrm{C}$. The harvested cells were resuspended in minimal M9 medium with antibiotics, $0.1 \mathrm{mM}$ IPTG, and $1 \mathrm{mM}$ p-coumaric acid as a substrate for resveratrol production. Fermentation continued at $25{ }^{\circ} \mathrm{C}$ for $20 \mathrm{~h} \mathrm{(160} \mathrm{rpm),} \mathrm{and} \mathrm{resveratrol} \mathrm{pro-}$ duction was analyzed by liquid chromatography-tandem mass spectrometry (LC-MS/MS) after $1.5 \mathrm{~h}, 4 \mathrm{~h}, 6 \mathrm{~h}, 8 \mathrm{~h}$, and $20 \mathrm{~h}$.

\section{Resveratrol LC-MS/MS analysis}

Resveratrol quantification was performed by an LC-MS/ MS analysis of the supernatant. The supernatant from $1 \mathrm{~mL}$ of fermentation broth was acidified with $6.25 \mu \mathrm{L}$ of $1 \mathrm{M} \mathrm{HCl}$ and heated to $95{ }^{\circ} \mathrm{C}$ for $5 \mathrm{~min}$. The sample was centrifuged at $17,000 \mathrm{rpm}(10 \mathrm{~min})$, and $600 \mu \mathrm{L}$ of the sample was analyzed using a Shimadzu Prominence Liquid Chromatographic system with the Accucore aQ $100 \mathrm{~mm} \times 2.1 \mathrm{~mm}, 2.6 \mu \mathrm{m}$ column (Thermo Scientific) at $30^{\circ} \mathrm{C}$. The sample $(2 \mu \mathrm{L})$ was separated at a flow rate of $400 \mu \mathrm{L} / \mathrm{min}$ using a linear acetonitrile $(\mathrm{MeCN}) /$ water gradient from $2 \% \mathrm{~B}$ to $70 \% \mathrm{~B}$ within 4.4 min (solvent A: $1 \% \mathrm{MeCN}, 99 \% \mathrm{H} 2 \mathrm{O}, 0.2 \% \mathrm{FA}$ (formic acid); solvent $\mathrm{B}$ : 99\% $\mathrm{MeCN}, 1 \% \mathrm{H} 2 \mathrm{O}, 0.2 \% \mathrm{FA})$. MS detection with an ESI source (Shimadzu LC-MS8030 triple quadruple) was performed in positive ion mode in N2 flow with a detector voltage of $4.5 \mathrm{kV}$. Quantification was performed in the multiple reaction monitoring (MRM) mode in a tandem mass spectrometer MS/MS to detect transitions $(\mathrm{m} / z)$ : for resveratrol $229 \rightarrow 107,134$, 91; for p-coumaric acid $165 \rightarrow 146,91,64$.

\section{Western blotting analysis}

Cells from $5 \mathrm{~mL}$ of fermentation broth were resuspended in $350 \mu \mathrm{L}$ of lysis buffer $(100 \mathrm{mM}$ Tris at pH 8.0, $100 \mathrm{mM}$ EDTA, $100 \mathrm{mM} \mathrm{MgCl} 2,1 \mathrm{mg} / \mathrm{mL}$ Lysozyme (SigmaAldrich), $15 \mathrm{U} / \mathrm{mL}$ Benzonase (Millipore), CPI protease 
inhibitors (Sigma-Aldrich)) and lysed at $25{ }^{\circ} \mathrm{C}$ for $1 \mathrm{~h}$. Proteins $(20 \mu \mathrm{L}$ of clear lysate) were separated on $12 \%$ SDS PAGE (sodium dodecyl sulfate-polyacrylamide gel electrophoresis) gels, blotted onto a Hybond ECL nitrocellulose membrane (GE Healthcare), and detected with mTetra-His antibodies (Qiagen) and goat anti-mouse HRP-conjugated antibodies (Jackson ImmunoResearch). ECL Western blotting detection reagent (GE Healthcare) was used for detection.

\section{Protein purification and native PAGE}

Escherichia coli BL21(DE3)pLysS strain was grown in an LB medium with antibiotics at $37{ }^{\circ} \mathrm{C}$ until $\mathrm{OD}_{600}$ reached 0.6 and then induced with $1 \mathrm{mM}$ IPTG and grown at $25^{\circ} \mathrm{C}$ for an additional $6 \mathrm{~h}$. The harvested cells were resuspended in a lysis buffer on ice $(100 \mathrm{mM}$ Tris at $\mathrm{pH} 8.0,50 \mathrm{mM} \mathrm{NaCl}, 10 \%(\mathrm{w} / \mathrm{v})$ glycerol, $1 \mathrm{mg} / \mathrm{mL}$ Lysozyme, $15 \mathrm{U} / \mathrm{mL}$ Benzonase, CPI protease inhibitors). Cell lysis was completed by sonication on ice for $2 \mathrm{~min}$ ( $5 \mathrm{~s}$ pulses) and then centrifuged at $12,000 \mathrm{rpm}\left(4^{\circ} \mathrm{C}\right)$ for $10 \mathrm{~min}$. The supernatant was filtered through a $0.22 \mu \mathrm{m}$ filter (Sartorius) and applied to the Ni-NTA column (Agarose Bead Technologies) for His-tagged-protein affinity isolation according to the manufacturer's protocol. Eluted fractions were collected and dialyzed against a $50 \mathrm{mM}$ Tris (pH 8.0) buffer containing $50 \mathrm{mM} \mathrm{NaCl}$ and $10 \%(\mathrm{w} / \mathrm{v})$ glycerol.

The isolated proteins were analyzed by native PAGE. The enzyme mixtures of $4 \mathrm{CL}$ and STS, with or without fused coiled-coil-forming domains $(0.8 \mathrm{mg} / \mathrm{mL}$ each), were prepared in a 1:1 molar ratio and incubated overnight at $4{ }^{\circ} \mathrm{C}$ or $25^{\circ} \mathrm{C}$. After the addition of native PAGE loading dye, the samples were separated on $8 \%$ separating gel at $100 \mathrm{~V}$ and $4{ }^{\circ} \mathrm{C}$ for $3 \mathrm{~h}$. The gel was stained using the Coomassie Brilliant Blue R-250.

\section{Co-isolation of proteins}

To confirm the interaction between two coiled-coilforming domains C-terminally fused to 4CL and STS ( $\left.{ }^{\mathrm{His}} 4 \mathrm{CL}: \mathrm{P3S},{ }^{\mathrm{AU}} \mathrm{STS}: \mathrm{P} 4 \mathrm{~S}\right)$, the co-isolation of recombinantly co-expressed proteins was performed on an $\mathrm{Ni}-$ NTA affinity column. As a negative control, ${ }^{\mathrm{His}} 4 \mathrm{CL}$ and ${ }^{\mathrm{AU}} \mathrm{STS}$ were used. After isolation, the samples were analyzed on $10 \%$ SDS PAGE gel.

\section{Yeast strain construction}

The plasmids used for the expression of Cas9 and the sgRNA to construct the carotenoid producing S. cerevisiae strain named CAR-0002 (Verwaal et al. 2018) were removed from the strain by liquid transfers on a YEP medium with $2 \%$ glucose (YEPD) and selections on YEPD agar plates with and without antibiotics. The open reading frames (ORFs) encoding the enzymes of the mevalonate biosynthetic pathway (acetyl-CoA acetyl transferase (ERG10), HMG-CoA synthase (HMGS), and truncated HMG-CoA reductase (tHMGR)) with or without an N-terminally fused P3:GCN:P4 coiled-coilforming domain were codon optimized for S. cerevisiae expression and ordered as synthetic DNA (ATUM). The ORFs were assembled into full expression cassettes by Golden-Gate cloning with promoter and terminator sequences and flanked by connector sequences as described by Roubos et al. (2013). A schematic representation of the expression cassettes is shown in Additional file 1: Fig. S1.

The (P3:GCN:P4)-ERG10, (P3:GCN:P4)-HMGS, and (P3:GCN:P4)-tHMGR expression cassettes were introduced into the genomic DNA of the carotenoidproducing yeast strain, which was constructed using the CRISPR/Cas9 approach described by Verwaal et al. (2018). The donor DNA cassettes were directed to the INT59 integration site, a non-coding region between SRP4O (YKR092C) and PTR2 (YKR093W) located on chromosome XI. The genomic target sequence for the sgRNA was AGAAAACTCTTAGCTTTTCC. Transformants were checked for the correct integration of the expression cassettes by PCR. Prior to growth experiments, transformants were cured from applied CRISPRediting plasmids by liquid transfers on YEP $2 \%$ glucose. All sequences used are available upon request.

\section{Yeast mevalonate and carotenoid production experiment}

Yeast cells were inoculated in a shake flask containing $20 \mathrm{~mL}$ of Verduyn medium with $2 \%$ glucose (Verduyn et al. 1992) and cultivated $48 \mathrm{~h}$ at $30^{\circ} \mathrm{C}$ and $250 \mathrm{rpm}$. One $\mathrm{mL}$ of the culture was transferred to a shake flask containing $50 \mathrm{~mL}$ of Verduyn medium with $2 \%$ glucose and cultivated an additional $72 \mathrm{~h}$.

\section{Mevalonate LC-MS/MS analysis}

Extracellular mevalonate quantification was performed by LC-MS/MS analysis. After $72 \mathrm{~h}$ of growth, $1 \mathrm{~mL}$ of fermentation broth was centrifuged to remove cells. The supernatant was diluted 100 times with milliQ water. Samples were analyzed by using a Waters iClass UPLC Liquid Chromatographic system with a Waters Acquity HSS T3 $150 \mathrm{~mm} \times 2.1 \mathrm{~mm}, 1.8 \mu \mathrm{m}$ column at $60^{\circ} \mathrm{C}$. An autosampler was set to $10^{\circ} \mathrm{C}$. A sample $(2 \mu \mathrm{L})$ was separated at a flow rate of $400 \mu \mathrm{L} / \mathrm{min}$. An acetonitrile/ammonium acetate elution started for $2 \mathrm{~min}$ at $100 \% \mathrm{~A}$ (solvent A: $25 \mathrm{mM}$ ammonium acetate) followed by a linear gradient to $95 \%$ B (solvent B: $100 \% \mathrm{MeCN}$ ) for 1 min and by a linear gradient to $50 \%$ B for $3 \mathrm{~min}$. MS/MS analysis was carried out using the Waters Xevo TQD triple quadruple mass spectrometer. MS detection with an ESI source was performed in negative ionization mode (capillary voltage 
$2 \mathrm{kV}$, cone voltage $20 \mathrm{~V}$, collision energy $10 \mathrm{~V}$, desolvation temperature $600{ }^{\circ} \mathrm{C}$, source temperature $150{ }^{\circ} \mathrm{C}$ ). Quantification was performed in the MRM mode in a tandem mass spectrometer MS/MS to detect transitions $(\mathrm{m} / \mathrm{z})$ for mevalonate $147 \rightarrow 86.6,58.8$.

\section{Carotenoid measurement}

Carotenoids were extracted using a PRECELLYS ${ }^{\circledR} 24$ tissue homogenizer. An equivalent of $20 \mathrm{OD}_{600}$ units (e.g., $2 \mathrm{~mL}$ with $\mathrm{OD}_{600}$ of 10) of culture was pelleted in a PRECELLYS tube, and the pellet was extracted with $1 \mathrm{~mL}$ of tetrahydrofuran (containing $0.01 \%$ butylhydroxytoluene) by homogenization for $3 \times 15 \mathrm{~s}$ at $6500 \mathrm{rpm}$. Following 5 min of centrifugation at $4{ }^{\circ} \mathrm{C}, 800 \mu \mathrm{L}$ was transferred to a glass vial. Extracts were dried down and resuspended in $80 \mu \mathrm{L}$ dichloromethane followed by $720 \mu \mathrm{L}$ of a $50 \%: 50 \%$ $(\mathrm{v} / \mathrm{v})$ mixture of heptane and ethyl acetate (containing $0.01 \%$ butylhydroxytoluene). A high-performance liquid choromatography (HPLC) analysis of carotenoids was performed, as described previously (Bailey et al. 2010).

\section{Nucleotide sequence accession numbers}

The nucleotide sequences of the codon-optimized synthetic genes for resveratrol production in $E$. coli were deposited at the Addgene database under accession numbers 139789, 139790, 139791, 139792, 139793, 139794, 139795, 139796, 139797, 139798, and 139799. The nucleotide sequences of the codon-optimized synthetic genes for mevalonate production in S. cerevisiae were deposited at the NCBI GenBank database under accession numbers 2308555, 2309511, 2309514, 2309522, 2309560, 2309561, 2309563, 2309567, and 2309569. The nucleotide sequences of the Cas9 plasmid and the sgRNA were deposited at the Addgene database under accession numbers 101725 and 101750, respectively (Verwaal et al. 2018).

\section{Results}

\section{Evaluating strategies of covalently fused enzymes}

We evaluated several protein clustering strategies for the two-step production of resveratrol from $\mathrm{p}$-coumaric acid (Fig. 1). As an initial attempt to generate macromolecular complexes in the biosynthetic pathway of resveratrol in $E$. coli, the enzymes 4-coumarate-CoA ligase (4CL) and stilbene synthase (STS) (Fig. 1a, b) were covalently fused via a genetically encoded construct using a 10 -amino acid linker (Fig. 1c, sequence in Additional file 1: Table S1). Surprisingly, the analysis of resveratrol production in E. coli cells transformed with pET19b-(4CL-STS) direct fusion and, supplemented with p-coumaric acid as a precursor, resulted in no detectable resveratrol accumulation (Fig. 2a) even though the Western blot analysis clearly showed the presence of a protein with a molecular size of $112 \mathrm{kDa}$, corresponding with the expected size of the fusion protein (Fig. 2b).

The second strategy for expressing covalently fused enzymes involved the use of split inteins. In this study, the $\mathrm{N}$-segment of the NpuDnaE split intein was fused to the $\mathrm{C}$-terminus of the $4 \mathrm{CL}$, and the $\mathrm{C}$-segment of the NpuDnaE split intein was fused to the $\mathrm{N}$-terminus of the STS. This should result in covalently fused 4CL and STS with a 10-amino acid linker (Fig. 1d, sequence in Additional file 1: Table S1), exactly as designed for the direct-fusion approach. This strategy successfully bypassed the potential folding problem inherent in fused multi-domain proteins, as confirmed by an analysis of a

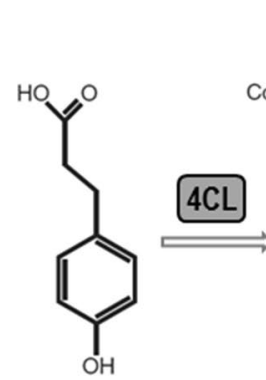

p-coumaric acid

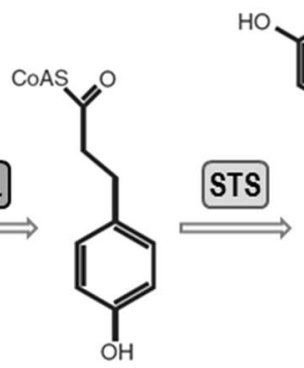

p-coumaroly $\mathrm{CoA}$ b

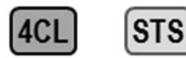

native enzymes

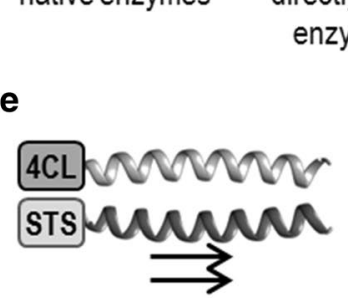

coiled coil in

parallel orientation

C

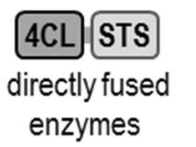

f

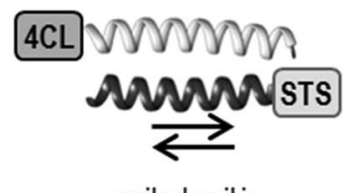

coiled coil in antiparallel orientation

Fig. 1 Schematic illustration of resveratrol biosynthesis and different strategies for the protein-based clustering of metabolic enzymes. a The enzymes 4-coumarate CoA ligase (4CL) and stilbene synthases (STS) are involved in resveratrol production from p-coumaric acid. $\mathbf{b}$ Native enzymes were used as a reference for resveratrol quantification. $\mathbf{c}, \mathbf{d}$ Two strategies were based on the covalent fusion of the enzymes 4CL and STS: direct genetically encoded fusion (c) and intein-mediated fusion (d). e, $\mathbf{f}$ The interactions of designed coiled-coil-forming domains bring both enzymes into proximity. Coiled-coil dimers can have either a parallel (e) or an antiparallel (f) orientation 

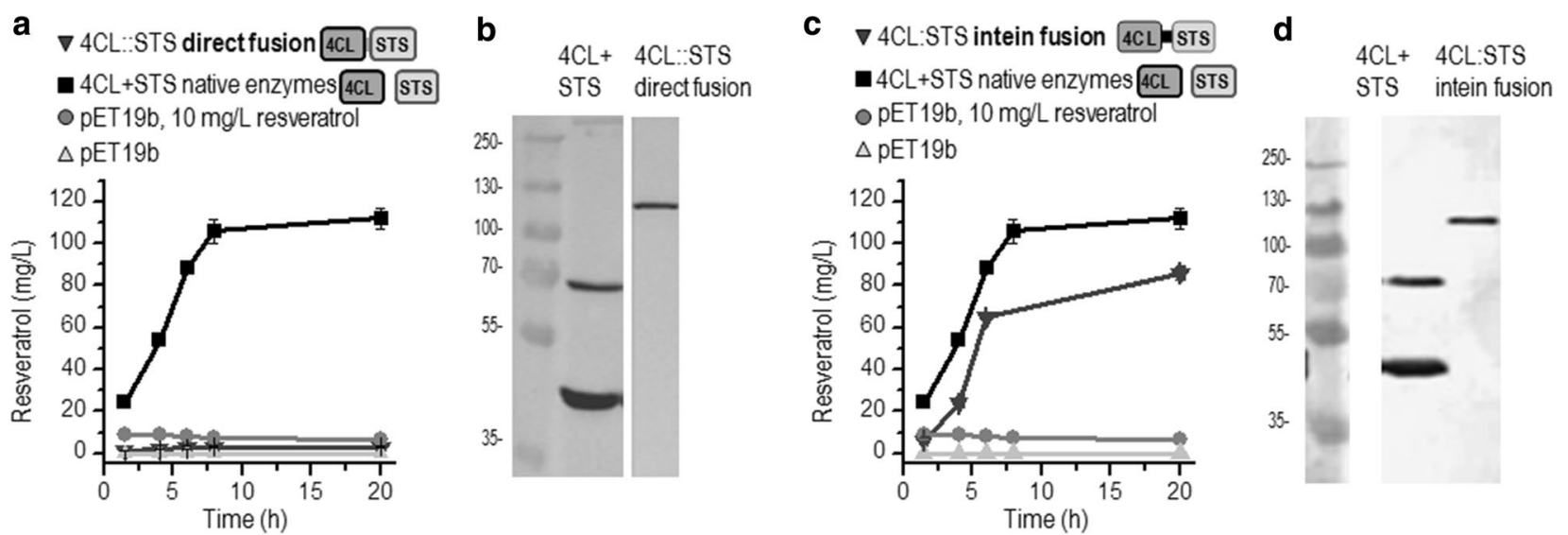

Fig. 2 Comparison of the efficiency of covalently fused enzymes for resveratrol production. Resveratrol accumulation in E. coli strains expressing a the directly fused enzymes (4CL::STS) and $\mathbf{c}$ the enzymes covalently coupled via split intein fusion (4CL:STS). Expression of the directly fused (b) and intein-fused (d) enzymes was determined by WB. Native enzymes (4CL + STS) were used for reference. The data represent the average and standard deviation of the representative fermentations from three independent experiments with similar results

resveratrol production and protein expression (Fig. 2c, d). The expression of protein $(112 \mathrm{kDa})$ corresponding to the expected size of the covalent split intein-mediated fusion was confirmed by Western blot (Fig. 2d), indicating virtually complete intein fusion. Within $20 \mathrm{~h}$ of the induction, the resveratrol production reached $83 \mathrm{mg} / \mathrm{L}$ (Fig. 2c). Nevertheless, the resveratrol production level was $25 \%$ lower when compared with the reference strain, where enzymes 4CL and STS were expressed separately but simultaneously. In comparison with the separately expressed enzymes, however, the band intensity of intein fusion was weaker (Fig. 2d), suggesting reduced protein expression or decreased stability, which may explain the lower level of resveratrol accumulation.

\section{Clustering of biosynthetic enzymes \\ through coiled-coil-forming domain interaction}

Another strategy was clustering enzymes through noncovalent interactions of small protein domains. Here, our aim was to test coiled-coil-forming domains for the improvement of biosynthetic reactions. To organize two enzymes from the resveratrol biosynthetic pathway into clusters, coiled-coil-forming domains were genetically fused to the $4 \mathrm{CL}$ and STS at their C-termini. The $4 \mathrm{CL}$ and STS were each fused to a coiled-coil-forming domain with the validated propensity for the formation of a heterodimeric coiled coil within its designed pairwise partner. The formation of a coiled-coil dimer brings the enzymes into proximity, where the distance between the enzyme domains can be varied by the parallel or antiparallel orientation between the coiled-coil partners (Fig. 1e, f).
First we checked a formation of the enzyme cluster through coiled-coil-forming domain interaction using a parallel heterodimer P3S/P4S from our set of coiled coils (sequences in Additional file 1: Table S2). After the coexpression of ${ }^{\mathrm{His}} 4 \mathrm{CL}: \mathrm{P} 3 \mathrm{~S}$ and ${ }^{\mathrm{AU}} \mathrm{STS}$ :P4S proteins in bacteria, the isolation was performed on the Ni-NTA affinity column, which selectively binds His-tagged proteins. We assumed that ${ }^{\mathrm{AU}} \mathrm{STS}$ :P4S protein co-isolates with the His 4CL:P3S protein if they form a P3S/P4S dimer based on the interaction of both coiled-coil-forming domains. This was indeed confirmed by SDS PAGE (Fig. 3a). In contrast, the two enzymes were not co-isolated in the coiled-coil-free enzymes ${ }^{\mathrm{His}} 4 \mathrm{CL}$ and ${ }^{\mathrm{AU}} \mathrm{STS}$ although the SDS PAGE analysis of the bacterial lysates revealed their expression (Fig. 3a). Next, the interaction between the coiled-coil-forming domains was also demonstrated by a native PAGE (Fig. 3b). The mixtures of the Ni-NTA isolated proteins ${ }^{\mathrm{His}} 4 \mathrm{CL}$ and ${ }^{\mathrm{His}} \mathrm{STS}$ or ${ }^{\mathrm{His}} 4 \mathrm{CL}: \mathrm{P} 3 \mathrm{~S}$ and

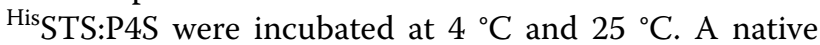
PAGE of a mixture containing 4CL:P3S and STS:P4S revealed a band of $\sim 200 \mathrm{kDa}$ (Fig. 3b), which corresponds to the complex 4CL:P3S/STS:P4S, confirming the interaction between coiled-coil-forming domains P3S and P4S. However, we could not detect any enzyme complex in a control mixture consisting of the enzymes 4CL and STS without fused coiled-coil forming domains (Fig. 3b).

\section{Coiled-coil fusions for in vivo bacterial resveratrol production}

We have further analyzed resveratrol production using coiled-coil-based enzyme clustering. The enzymes 4CL and STS were fused to coiled-coil-forming domains with different dimer stabilities and orientations (Fig. 1e, f). 


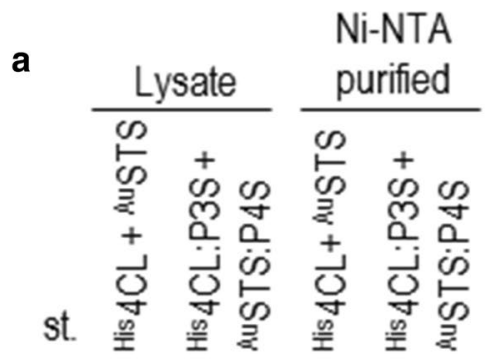

b
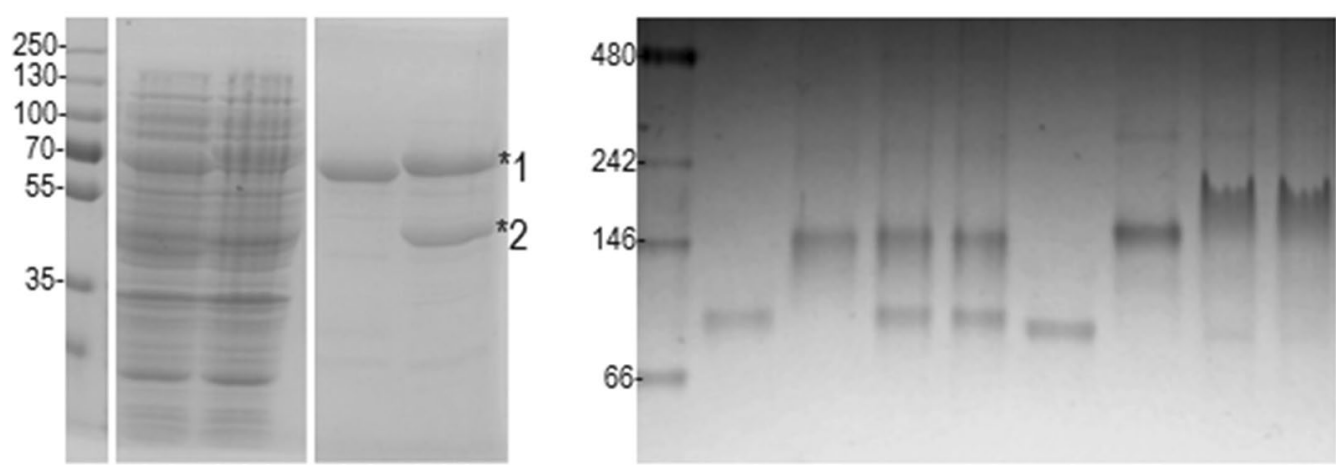

Fig. 3 NiNTA-isolated coiled-coil-forming domains fused with enzymes interact and form clusters in vitro. a The SDS PAGE of the NiNTA-isolated proteins demonstrates the interaction between P3S and P4S from fusion proteins ${ }^{H i s} 4 \mathrm{CL}: \mathrm{P} 3 \mathrm{~S}\left({ }^{*} 1\right)$ and ${ }^{\mathrm{AU}} \mathrm{STS}: \mathrm{P} 4 \mathrm{~S}\left({ }^{*} 2\right)$. b Native PAGE analysis revealed that in vitro clusters of $4 \mathrm{CL}$ and STS are formed at two different temperatures only on the fusion of enzymes with the coiled-coil-forming segments P3S and P4S

Several parallel coiled coils (Fig. 1e) with different levels of stability and helical propensity were therefore selected from our set: from the most stable pair, $\mathrm{P} 5 \mathrm{SHb} / \mathrm{P} 6 \mathrm{SHb}$, followed by $\mathrm{P} 3 \mathrm{~S} / \mathrm{P} 4 \mathrm{~S}$, to the less stable pairs, $\mathrm{P} 7 \mathrm{SHb} /$ $\mathrm{P} 8 \mathrm{SHb}$ and P7S/P8S, respectively (sequences in Additional file 1: Table S2) (Drobnak et al. 2017). In addition, an antiparallel coiled-coil-forming pair, P3S-AP4S (Fig. 1f), was tested to check whether the close proximity of the enzymes in parallel variants (Fig. 1e) might be hindered sterically and what the effect of the distance between the enzymes is.

The enzymes fused to the most stable coiled coil, $\mathrm{P} 5 \mathrm{SHb}-\mathrm{P} 6 \mathrm{SHb}$, resulted in the highest resveratrol titer $(145 \mathrm{mg} / \mathrm{L})$ after $8 \mathrm{~h}$ of cultivation (Fig. $4 \mathrm{a}$ and Additional file 1: Fig. S2a). This was followed by a fusion protein with a slightly less stable coiled coil, P3S-P4S (125 mg/L). No significant differences in resveratrol accumulation were observed when using the parallel (P3S-P4S) or

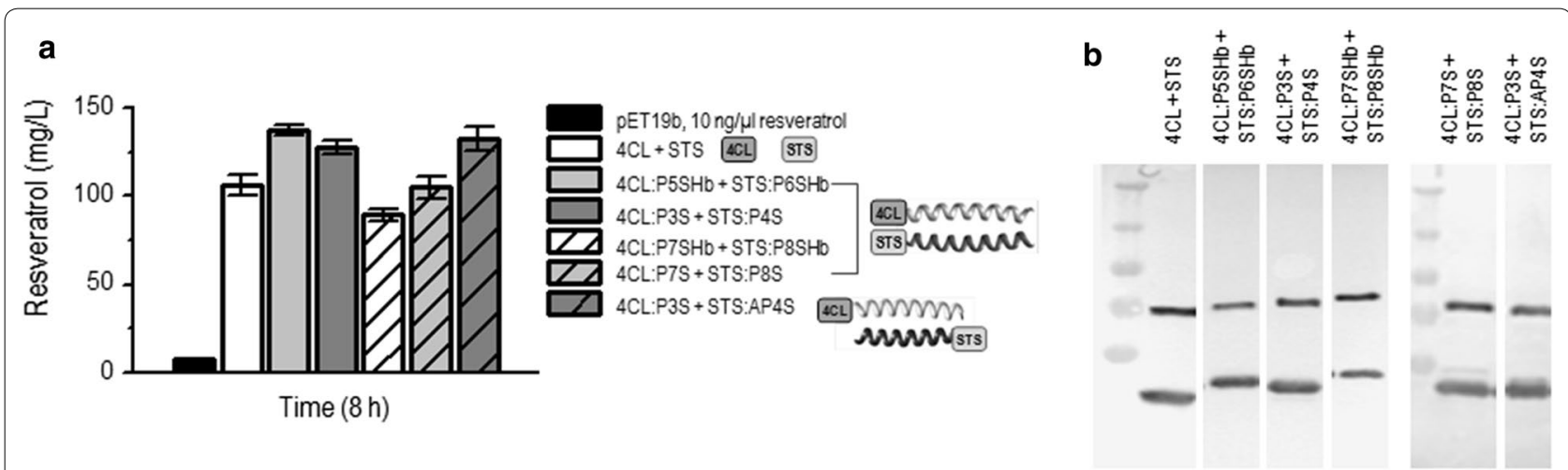

Fig. 4 The clustering of biosynthetic enzymes via coiled-coil-forming domains improves resveratrol production in E. coli. a Enhancement of resveratrol biosynthesis in $E$. coli after $8 \mathrm{~h}$, depending on the type of coiled-coil-forming domain fused to the enzymes. Simultaneously expressed native enzymes (4CL + STS) served as a reference. $\mathbf{b}$ The expression of enzymes coupled via coiled-coil-forming domain fusion was determined by WB. The same protein expression in three representative fermentations is shown in Additional file 1: Fig. S2 
antiparallel (P3S-AP4S) coiled-coil variants. In all three coiled-coil fusions described above, resveratrol accumulation was significantly improved in comparison with the control strain with native enzymes $(110 \mathrm{mg} / \mathrm{L})$. Two of the selected coiled-coil pairs with low thermal stability, P7SHb-P8SHb and P7S-P8S, resulted in slightly lower titers than the control strain. However, all the fused proteins were expressed at the same level as determined by Western blot (Fig. $4 \mathrm{~b}$ and Additional file 1: Fig. S2b). Additional file 1: Figure S2 shows the time course for resveratrol production and the expression of proteins when different enzyme-coiled-coil pairs were expressed in $E$. coli. We conclude, therefore, that a higher stability of a coiled-coil pair in enzyme fusion leads to a higher level of resveratrol production for around $30 \%$ in comparison to native enzymes.

\section{Coiled-coil fusions for the mevalonate production in yeast}

Finally, the coiled-coil scaffold-fused enzymes were introduced into $S$. cerevisiae, modifying three enzymes required for the production of mevalonate: ERG10, HMGS, and tHMGR. The scaffold-forming polypeptide was composed of three concatenated coiled-coil-forming domains: a homodimer-forming GCN, a heterodimerforming P3, and a heterodimer-forming P4, which were designed to form a coiled-coil-mediated network. The fusion polypeptide P3:GCN:P4 was N-terminally fused to each of the mevalonate biosynthetic enzymes (Fig. 5a). The expression of enzymes with or without scaffoldforming domains was under the control of constitutive promoters. The yeast fermentations demonstrated an 8.8- fold increase in mevalonate accumulation after $72 \mathrm{~h}$ in strains where the mevalonate enzymes were clustered through scaffold formation in comparison to strains expressing non-scaffolded enzymes (Fig. 5b). Mass spectrometric analysis of the enzymes showed equal protein expression (data not shown), suggesting that the increased yield occurred due to scaffolding rather than due to the increased number of enzymes. Although the overexpression of non-scaffolded mevalonate pathway enzymes resulted in the increased production of carotenoids, a similar significant increase as that seen for mevalonate was not observed with scaffolded enzymes (Fig. 5c).

\section{Discussion}

The clustering of biosynthetic enzymes can be achieved through different strategies, including direct fusion (Zhang et al. 2006), intein-mediated fusion (Selgrade et al. 2013), and fusion with natural or designed interaction domains (Conrado et al. 2012; Diener et al. 2016; Han et al. 2017; Yang et al. 2017). However, protein-based scaffolds as enzyme clustering principle have, since they

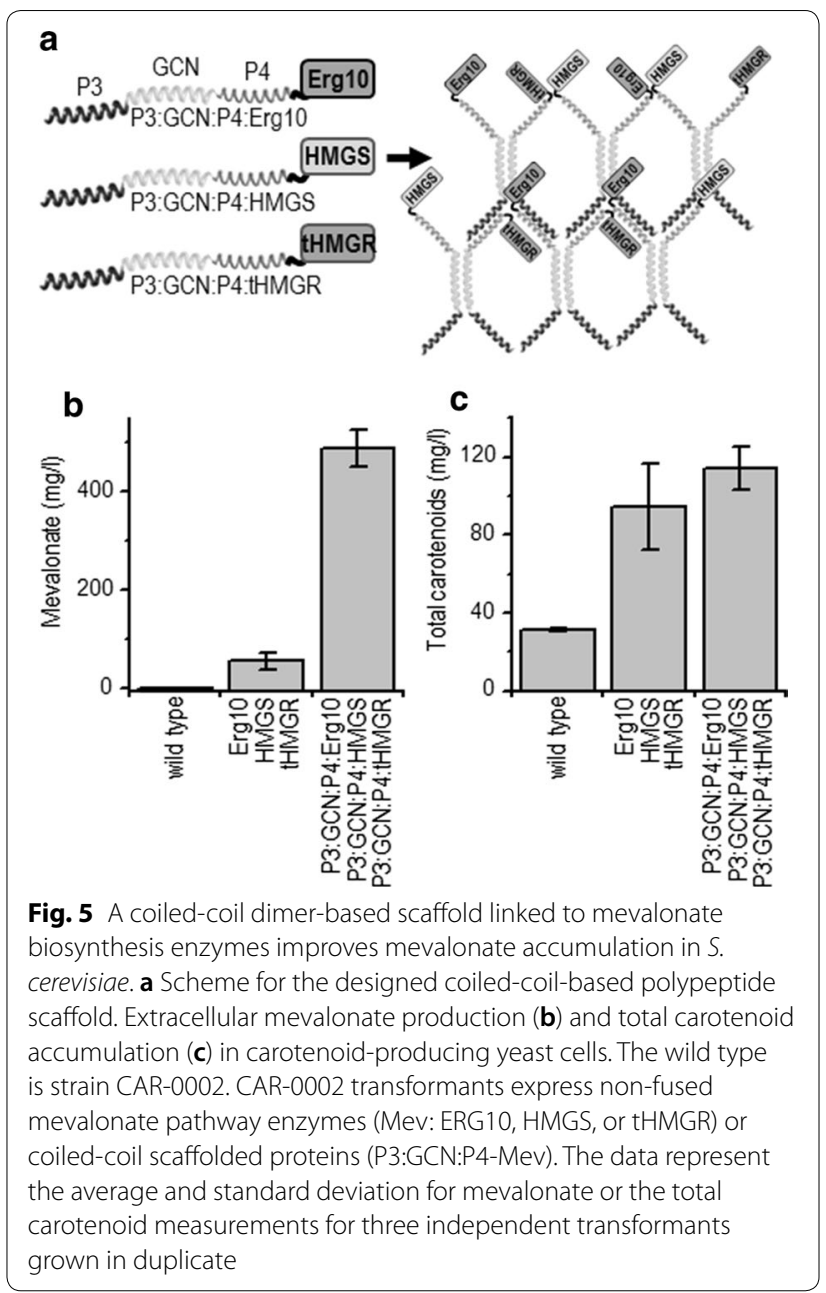

were reported, demonstrated use in different biosynthetic reactions. Most of the results demonstrated based on protein-peptide domain interactions (e.g., SH3, PDZ, GBD), where the binding domains were relatively large and were based on different protein folds, may have different physicochemical properties and may interfere with natural ligands, particularly in eukaryotic cells. Coiled-coil dimers, alternatively, are available in several orthogonal sets (Gradišar and Jerala 2011; Reinke et al. 2013), have similar properties, and are relatively small in comparison to the enzymes. The use of a coiled-coil single leucine zipper pair has been previously reported to increase the production of 1-butanol (Han et al. 2017); however, here we report on the use of a set of orthogonal coiled-coil pairs (Drobnak et al. 2017), which can be tuned for stability and are designed de novo to avoid interference with natural coiled coils.

We tested several strategies of enzyme clustering, and as a model we chose metabolic enzymes $4 \mathrm{CL}$ and STS from a resveratrol metabolic pathway. First, we prepared 
a direct fusion of both enzymes. The fusion protein was expressed, but the enzyme activity was not detected. Although direct fusion has been reported to generate functional fused proteins that produce resveratrol in yeast (Zhang et al. 2006), the misfolding of the fused enzymes either due to the steric hindrance during protein folding or caused by the lack of required folding chaperones inside the $E$. coli cells could be responsible for the failure of this strategy.

We assumed that the strategy using split inteins could lead to a functional enzyme fusion. Inteins are self-splicing elements that can generate fused polypeptide chains from a pair of separately translated polypeptide chains with virtually no remaining scars (Shah and Muir 2011; Aranko et al. 2014). The main advantage of this approach, in comparison with direct protein fusion, is the independent folding of each individual enzyme as they are fused to a relatively small split intein domain, thereby eliminating the mutual folding interference between the polypeptide chains. Each split intein segment is fused to an individual enzyme domain and is coded, transcribed, and translated separately. After translation, pairs of proteins with separate split domains interact and can form a covalent bond in which virtually all the intein amino acid sequence is excised from the final fusion protein. Our results confirmed the expression of intein-based fusion, but the production of resveratrol was $25 \%$ lower compared to the reference separately but simultaneously expressed enzymes 4CL and STS.

An alternative strategy for bringing biosynthetic enzymes into proximity involves inducing noncovalent clustering mediated by small protein interaction domains. By adding short protein interacting domains at the $\mathrm{N}$ - or $\mathrm{C}$-terminus of both enzyme partners, stable noncovalent protein clusters can be expressed. To combine more than a single pair of catalytic domains selectively, several orthogonal interaction partners are needed, which could be provided by an orthogonal set of designed coiled-coil dimers. Previously, we designed such a toolbox of several orthogonal heterodimeric coiled coils (Gradišar and Jerala 2011; Drobnak et al. 2017), reporting on their application as modular building blocks for in vitro and in vivo protein-cage formation (Gradišar et al. 2013; Ljubetič et al. 2017).

First, we proved a formation of enzyme clusters through coiled-coil-forming domain interaction. Using fusions between enzymes and coiled-coil-forming domains, 4CL:P3S and STS:P4S, respectively, we showed that complex 4CL:P3S/STS:P4S was formed. For the production of resveratrol, we tested several parallel coiled coils with different levels of stability and helical propensity. For the most stable pairs, $\mathrm{P} 5 \mathrm{SHb} / \mathrm{P} 6 \mathrm{SHb}$ and $\mathrm{P} 3 \mathrm{~S} / \mathrm{P} 4 \mathrm{~S}$, the production of resveratrol increased up to $30 \%$ compared to the reference. Further, the resveratrol production was comparable for enzyme fusions with parallel coiledcoil P3S/P4S and its antiparallel variant P3S/AP4S. This result suggests that at least in the case of enzymes on the resveratrol pathway, small differences in enzyme proximity due to the coiled-coil orientation $(\sim 4 \mathrm{~nm})$ do not significantly influence the overall biosynthetic yield. Overall, the results indicate that coiled-coil-based dimers increase the biosynthetic product yield for resveratrol and that the improvement is correlated with coiled-coil stability. In the experiments, the amounts of free and coiled-coilfused enzymes did not vary significantly. It is also possible that coiled-coil fusion may increase enzyme stability or proteolytic resistance, which could also contribute to increased yields.

Finally, to investigate whether the coiled-coil protein fusion platform could be extended to other organisms and could be used for the biosynthesis of other multicatalytic-step biosynthetic products, the coiled-coil scaffold-fused enzymes were introduced into S. cerevisiae. We prepared enzyme fusions with domains composed of three coiled-coil-forming segments that can form not only dimers but larger scaffolds. The constructs were transformed into yeast strain CAR0002, which contains the carotenoid biosynthesis pathway from Xanthoplyllomyces dendrorhous (Zhang et al. 2006). In this pathway, mevalonate serves as a precursor for carotenoid production, thus measuring the carotenoid production serves as an additional reporter of mevalonate production. After $72 \mathrm{~h}$, the production of mevalonate was remarkably higher (8.8-fold induction) compared to the control (non-scaffolded enzymes). The carotenoid amount had also increased, but the difference was not significant. Larger increases may be observed when flux through the carotenoid pathway is improved, such as by the introduction of additional copies of carotenogenic genes (Verwaal et al. 2007). In summary, these results demonstrate that coiled-coil-based enzyme clustering is also functional in yeast.

Although different biosynthetic pathways cannot be compared directly, our results show that the yield improvement was largest in the case of concatenated coiled-coil-forming domains. This is likely due to the potential to lead to the formation of larger clusters, which has been proposed to be required for an increased biosynthetic yield (Lee et al. 2012). In the future, the availability of our large set of designed orthogonal coiled-coil dimers/oligomers will enable the design of defined clusters for multi-component biosynthetic pathways. 


\section{Supplementary information}

Supplementary information accompanies this paper at https://doi. org/10.1186/s13568-020-01031-5.

Additional file 1. The additional information accompanies this paper at https://amb-express.springeropen.com/.

\section{Abbreviations}

CC: Coiled coil; 4CL: 4-coumaroyl-CoA ligase; STS: Stilbene synthase; Erg10: Acetyl-CoA acetyl transferase; HMGS: HMG-CoA synthase; tHMGR: Truncated HMG-CoA reductase.

\section{Acknowledgements}

This project was financed by the Slovenian Research Agency (projects L4-6812 and J3-7034, program P4-0176) and by a grant from the ICGEB (CRP/SLO1403). We would like to thank Robert Bremšak for assistance in the MS analysis.

\section{Authors' contributions}

$R V$, JAR, RJ, and HG conceived and designed research. TF, BS, RG, and MB conducted experiments on E. coli and analyzed the data. RV and RG conducted experiments on S. cerevisiae and analyzed the data. TF, RV, RJ, and HG wrote the manuscript. All authors read and approved the manuscript.

\section{Funding}

This research was funded by the Slovenian Research Agency (projects L4-6812 and J3-7034, program P4-0176) and by a grant from the ICGEB (CRP/ SLO14-03).

\section{Availability of data and materials}

Corresponding author could provide all the experimental data on valid request.

The nucleotide sequences of the codon-optimized synthetic genes were deposited at the Addgene and NCBI GenBank databases. The accession numbers are listed in the section Materials and methods.

\section{Ethics approval and consent to participate}

Not applicable.

\section{Consent for publication}

Not applicable.

\section{Competing interests}

The authors declare that they have no competing interests.

\section{Author details}

${ }^{1}$ Department of Synthetic Biology and Immunology, National Institute of Chemistry, Hajdrihova 19, 1000 Ljubljana, Slovenia. ${ }^{2}$ DSM Biotechnology Center, DSM, Delft, The Netherlands. ${ }^{3}$ EN-FIST Centre of Excellence, Ljubljana, Slovenia.

Received: 3 April 2020 Accepted: 16 May 2020

Published online: 24 May 2020

\section{References}

Aranko AS, Wlodawer A, Iwaï H (2014) Nature's recipe for splitting inteins. Protein Eng Des Sel 27:263-271. https://doi.org/10.1093/protein/gzu028

Bailey R, Madden KT, and Trueheart J (2010) Production of carotenoids in oleaginous yeast and fungi, US7851199B2, 2010

Castellana M, Wilson MZ, Xu Y, Joshi P, Cristea IM, Rabinowitz JD, Gitai Z, Wingreen NS (2014) Enzyme clustering accelerates processing of intermediates through metabolic channeling. Nat Biotechnol 32:1011-1018. https ://doi.org/10.1038/nbt.3018

Colin PY, Zinchenko A, Hollfelder F (2015) Enzyme engineering in biomimetic compartments. Curr Opin Struct Biol 33:42-45. https://doi.org/10.1016/j. sbi.2015.06.001
Conrado RJ, Varner JD, DeLisa MP (2008) Engineering the spatial organization of metabolic enzymes: mimicking nature's synergy. Curr Opin Biotechnol 19:492-499. https://doi.org/10.1016/j.copbio.2008.07.006

Conrado RJ, Wu GC, Boock JT, Xu H, Chen SY, Lebar T, Turnšek J, Tomšič N, Avbelj M, Gaber R, Koprivnjak T, Mori J, Glavnik V, Vovk I, Benčina M, Hodnik V, Anderluh G, Dueber JE, Jerala R, DeLisa MP (2012) DNAguided assembly of biosynthetic pathways promotes improved catalytic efficiency. Nucleic Acids Res 40:1879-1889. https://doi.org/10.1093/nar/ gkr888

Delebecque CJ, Lindner AB, Silver PA, Aldaye FA (2011) Organization of intracellular reactions with rationally designed RNA assemblies. Science 333:470-474. https://doi.org/10.1126/science.1206938

Diener M, Kopka B, Pohl M, Jaeger KE, Krauss U (2016) Fusion of a coiledcoil domain facilitates the high-level production of catalytically active enzyme bodies. Chem Cat Chem 8:142-152. https://doi.org/10.1002/ cctc.201501001

Drobnak I, Gradišar H, Ljubetič A, Merljak E, Jerala R (2017) Modulation of coiled-coil dimer stability through surface residues while preserving pairing specificity. J Am Chem Soc 139:8229-8236. https://doi.org/10.1021/ jacs.7b01690

Dueber JE, Wu GC, Malmirchegini GR, Moon TS, Petzold CJ, Ullal AV, Prather KLJ, Keasling JD (2009) Synthetic protein scaffolds provide modular control over metabolic flux. Nat Biotechnol 27:753-759. https://doi.org/10.1038/ nbt.1557

Gradišar H, Jerala R (2011) De novo design of orthogonal peptide pairs forming parallel coiled-coil heterodimers. J Pept Sci 17:100-106. https://doi. org/10.1002/psc.1331

Gradišar H, Božič S, Doles T, Vengust D, Hafner-Bratkovič I, Mertelj A, Webb B, Šali A, Klavžar S, Jerala R (2013) Design of a single-chain polypeptide tetrahedron assembled from coiled-coil segments. Nat Chem Biol 9:362-366. https://doi.org/10.1038/nchembio.1248

Halls C, Yu O (2008) Potential for metabolic engineering of resveratrol biosynthesis. Trends Biotechnol 26:77-81. https://doi.org/10.1016/j.tibte ch.2007.11.002

Han GH, Seong W, Fu Y, Yoon PK, Kim SK, Yeom SY, Lee DH, Lee SG (2017) Leucine zipper-mediated targeting of multi-enzyme cascade reactions to inclusion bodies in Escherichia coli for enhanced production of 1-butanol. Metab Eng 40:41-49. https://doi.org/10.1016/j.ymben.2016.12.012

Jandt U, You C, Zhang YHP, Zeng AP (2013) Compartmentalization and metabolic channeling for multienzymatic biosynthesis: practical strategies and modeling approaches. Adv Biochem Eng Biotechnol 137:41-65. https:// doi.org/10.1007/10_2013 221

Ji Q, Wang B, Tan J, Zhu L, Li L (2016) Immobilized multienzymatic systems for catalysis of cascade reactions. Process Biochem 51:1193-1203. https:// doi.org/10.1016/j.procbio.2016.06.004

Ke Y, Meyer T, Shih WM, Bellot G (2016) Regulation at a distance of biomolecular interactions using a DNA origami nanoactuator. Nat Commun 7:10935-10942. https://doi.org/10.1038/ncomms10935

Lee H, DeLoache WC, Dueber JE (2012) Spatial organization of enzymes for metabolic engineering. Metab Eng 14:242-251. https://doi.org/10.1016/j. ymben.2011.09.003

Li T, Chen X, Cai Y, Dai J (2018) Artificial Protein Scaffold System (AProSS): an efficient method to optimize exogenous metabolic pathways in Saccharomyces cerevisiae. Metab Eng 49:13-20. https://doi.org/10.1016/j.ymben 2018.07 .006

Lim S, Jung GA, Glover DJ, Clark DS (2019) Enhanced enzyme activity through scaffolding on customizable self-assembling protein filaments. Small 15:1805558. https://doi.org/10.1002/smll.201805558

Ljubetič A, Lapenta F, Gradišar H, Drobnak I, Aupič J, Strmšek Ž, Lainšček D, Hafner-Bratkovič I, Majerle A, Krivec N, Benčina M, Pisanski T, Ćirković Veličković T, Round A, Carazo JM, Melero R, Jerala R (2017) Design of coiled-coil protein-origami cages that self-assemble in vitro and in vivo. Nat Biotechnol 35:1094-1101. https://doi.org/10.1038/nbt.3994

Polka JK, Hays SG, Silver PA (2016) Building spatial synthetic biology with compartments, scaffolds, and communities. Cold Spring Harb Perspect Biol. https://doi.org/10.1101/cshperspect.a024018

Reinke AW, Baek J, Ashenberg O, Keating AE (2013) Networks of bZIP proteinprotein interactions diversified over a billion years of evolution. Science 340:730-734. https://doi.org/10.1126/science.1233465

Roubos JA, Pel HJ, Meijrink B (2013) Cloning method. EP2831238B1 
Sachdeva G, Garg A, Godding D, Way JC, Silver PA (2014) In vivo co-localization of enzymes on RNA scaffolds increases metabolic production in a geometrically dependent manner. Nucleic Acids Res 42:9493-9503. https:// doi.org/10.1093/nar/gku617

Schmidt-Dannert S, Zhang G, Johnston T, Quin MB, Schmidt-Dannert C (2018) Building a toolbox of protein scaffolds for future immobilization of biocatalysts. Appl Microbiol Biotechnol 102:8373-8388. https://doi. org/10.1007/s00253-018-9252-6

Selgrade DF, Lohmueller JJ, Lienert F, Silver PA (2013) Protein scaffold-activated protein trans-splicing in mammalian cells. J Am Chem Soc 135:77137719. https://doi.org/10.1021/ja401689b

Shah NH, Muir TW (2011) Split inteins: nature's protein ligases. Isr J Chem 51:854-861. https://doi.org/10.1002/ijch.201100094

Verduyn C, Postma E, Scheffers WA, van Dijken JP (1992) Effect of benzoic acid on metabolic fluxes in yeasts. Yeast 8:501-517. https://doi.org/10.1007/ BF00270792

Verwaal R, Wang J, Meijnen JP, Visser H, Sandmann G, van den Berg JA, van Ooyen AJJ (2007) High-level production of beta-carotene in Saccharomyces cerevisiae by successive transformation with carotenogenic genes from Xanthophyllomyces dendrorhous. Appl Environ Microbiol 73:43424350. https://doi.org/10.1128/AEM.02759-06

Verwaal R, Buiting-Wiessenhaan N, Dalhuijsen S, Roubos JA (2018) CRISPR/ Cpf1 enables fast and simple genome editing of Saccharomyces cerevisiae. Yeast 35:201-211. https://doi.org/10.1002/yea.3278

Wang Y, Yu O (2012) Synthetic scaffolds increased resveratrol biosynthesis in engineered yeast cells. J Biotechnol 157:258-260. https://doi. org/10.1016/j.jbiotec.2011.11.003
Wang Y, Yi H, Wang M, Yu O, Jez JM (2011) Structural and kinetic analysis of the unnatural fusion protein 4-coumaroyl-CoA ligase:stilbene synthase. J Am Chem Soc 133:20684-20687. https://doi.org/10.1021/ja2085993

Yang Z, Gao X, Xie H, Wang F, Ren Y, Wei D (2017) Enhanced itaconic acid production by self-assembly of two biosynthetic enzymes in Escherichia coli. Biotechnol Bioeng 114:457-462. https://doi.org/10.1002/bit.26081

Zhang Y, Li SZ, Li J, Pan X, Cahoon RE, Jaworski JG, Wang X, Jez JM, Chen F, Yu $O$ (2006) Using unnatural protein fusions to engineer resveratrol biosynthesis in yeast and mammalian cells. J Am Chem Soc 128:13030-13031. https://doi.org/10.1021/ja0622094

Zhang G, Quin MB, Schmidt-Dannert C (2018) Self-assembling protein scaffold system for easy in vitro coimmobilization of biocatalytic cascade enzymes. ACS Catal 8:5611-5620. https://doi.org/10.1021/acscatal.8b009 86

Zhang G, Johnston T, Quin MB, Schmidt-Dannert C (2019) Developing a protein scaffolding system for rapid enzyme immobilization and optimization of enzyme functions for biocatalysis. ACS Synth Biol 8:1867-1876. https://doi.org/10.1021/acssynbio.9b00187

\section{Publisher's Note}

Springer Nature remains neutral with regard to jurisdictional claims in published maps and institutional affiliations.

\section{Submit your manuscript to a SpringerOpen ${ }^{\circ}$ journal and benefit from:}

- Convenient online submission

- Rigorous peer review

- Open access: articles freely available online

- High visibility within the field

- Retaining the copyright to your article

Submit your next manuscript at $\boldsymbol{\nabla}$ springeropen.com 